\title{
Permeability Estimation Model from Grain Size Sieve Analysis: Data of Onshore Central Niger Delta
}

\author{
Chikwendu E. Ubani, Goodness O. Ani, and Toluope T. Womiloju
}

\begin{abstract}
Permeability is an important property of the soil and studies have shown that grain size distribution is a controlling factor to this property. Establishing an empirical equation that shows the relationship between permeability and grain size has been previously investigated by several researchers, all of whom have been able to develop models for fast permeability prediction using grain size data. But because of the complexity of permeability and the Earth's anisotropic nature, the confidence level of using this models is low as was seen when a comparison was carried out in this project using some of these models. The aim of this project is to develop a model using grain sieve analysis data for permeability prediction tailored to the Niger Delta region. Using statistica7 software, multiple regression analysis was performed on the grain size distribution data from sieve analysis using parameters P10, P90 and mean grain size distribution. Three models were developed for permeability ranges of less than $10 \mathrm{mD}$ to greater than $10000 \mathrm{mD}$ with $R 2$ values of $(0.857,0.820$, 0.939) showing a good data and regression fitting and $R$ values of $(0.926,0.906,0.969)$ showing strong positive correlation between variables. Permeability values obtained from routine core analysis was compared to the predicted permeability gotten from the model equation produced by the regression analysis. The models displayed good correlation with the routine core analysis values as seen on the validation charts plotted. A coloured schemed 3-D surface plot was generated to display the integrated effect of the grain size and density on permeability. The sensitivity analysis carried out showed that proper grain sorting is essential in permeability prediction.
\end{abstract}

Index Terms -Permeability; Grain Size; Niger Delta Region; P10 and P90 Percentile; Routine Core Analysis.

\section{INTRODUCTION}

Recovering of hydrocarbons from the reservoir is the essence of petroleum exploration and permeability prediction or estimation aids in the determination of the quantity that can be recovered from a reservoir. Permeability is a measure of the ease of flow of liquid through a porous media [1], [2]. The knowledge of permeability is an important parameter in determining flow characteristics for hydrocarbon reservoirs and ground water aquifers. It is also used during reservoir stimulation and rock type descriptions. Permeability is measured in $\mathrm{m}^{2}$, but practically in Darcy (D) or milli-Darcy $(\mathrm{mD}),\left(1 \mathrm{D} \approx 10^{-12} \mathrm{~m}^{2}\right)$.

Published on December 25, 2018

C. E. Ubani is presently with the Department of Petroleum and Gas Engineering, University of Port Harcourt, PMB 5323, Rivers State, Nigeria. (chikweubani@yahoo.com, chikwendu.ubani@uniport.edu.ng).

G. O. Ani is presently with the Department of Petroleum and Gas Engineering, University of Port Harcourt, PMB 5323, Rivers State, Nigeria. (gpasting@gmail.com, goodness.ani@uniport.edu.ng)

T. T. Womiloju was a Master Student at the Center of Petroleum Geoscience (CPG), University of Port Harcourt, PMB 5323, Rivers State, Nigeria.
Permeability is defined in three types, based on the flow of hydrocarbon in the reservoir:

Absolute permeability $\left(K_{a}\right)$ : Permeability calculated with only one fluid present in the pores of a formation is called absolute permeability.

Effective Permeability $\left(K_{e}\right)$ : the permeability of a formation with immiscible fluids but able to conduct one fluid in the presence of the other(s) is called Effective Permeability $\left(\mathrm{K}_{\mathrm{e}}\right)$.

Relative Permeability $\left(K_{r}\right)$ : this is the ratio of effective permeability of a fluid to the formation's absolute permeability (100\% saturated with that fluid).

Permeability measurement is performed in the Laboratory using a permeameter, this measures the flows of liquid or gas through a samples. Another method of measuring or predicting permeability is by estimating from logs by the use of different equations such as Timur, Tixier, etc. and in situ Darcy test for horizontal permeability [3] and shallow zones [4].

Grain size and other variables such as porosity, density, sorting, grain packing, and grain shape are essential is permeability determination of unconsolidated soils and as such used to establish empirical equations for the estimation of permeability. Researchers such as [5], and many others made efforts in developing empirical equations for predicting permeability from grain size, porosity, sorting, packing and grain shapes.

Darcy's law (fundamental relationship) gives the basis for permeability determination. Darcy law was transformed into an equation, given as:

$$
\mathrm{q}=\mathrm{kA} \frac{\Delta \mathrm{h}}{\mathrm{l}}
$$

Further investigations into Darcy law reveals that the constant of proportionality ' $\mathrm{K}$ ', if replaced by ' $\mathrm{K} / \mu$ ' can be extended to other liquids. This modification makes Darcy's law suitable for this study as:

$$
\mathrm{q}=-\frac{\mathrm{KA}}{\mu \mathrm{L}} \Delta \mathrm{P}
$$

Where; $\mathrm{k}$ is the Permeability of the rock $(\mathrm{mD}), \mathrm{q}$ is flowrate $\left(\mathrm{cm}^{3} / \mathrm{s}\right), \mu$ is the Viscosity of the fluid flowing through the rock $(\mathrm{cP}), \mathrm{A}$ is Cross-sectional area $\left(\mathrm{cm}^{2}\right), \mathrm{L}$ is Length $(\mathrm{cm}), \Delta \mathrm{P}$ is Pressure change (atm).

Empirical based equations are not assuredly transferrable from region to region due to soil heterogeneity [6]. Sediments in the Niger Delta are deposited in layers which can make them exhibit anisotropies. Therefore, it is imperative to determine the appropriate equation for the Niger delta basin. 
This work aimed at developing a model that predicts permeability from grain size sieve analysis, in the Niger Delta Region. Empirical relationship to predict/estimate permeability for Niger delta basin using grain size sieve analysis data will be established, the result obtained will be correlated with results from standard routine core analysis as a check means for accuracy and compare with a previous developed models.

\section{FACTORS CONTROLLING PERMEABILITY}

Permeability is an intricate property that is affected by physical properties of the soil and the fluid passing through it. [3]. In sandstones, grain size, size distribution, grain orientation, grain packing and arrangement, cementation, clay content, bedding and sorting controls how permeable the rock unit is. In carbonates, permeability is controlled by the degree of mineral diagenetic change (dolomitization), fractures and porosity development [7], [8].

\section{A. Porosity:}

For a system to be permeable, it must have interconnected pore spaces (Porosity), and the relationship between permeability and porosity, which in most cases is said to be linear i.e, as porosity increase, permeability increase.

\section{B. Grain Texture and Structure:}

This relates to the arrangement of grains, its shape and size in the rock unit, grain shape influences its size and the interconnection of the pores. The less rounded the grains are, the smaller the pore spaces and more tortuous the flow paths [2].

\section{Grain Packing and Confining Pressures:}

Packing refers to the spacing and density of grains. Strongly lithified rocks (more dense) have reduced permeability under confining pressure.

\section{Grain Density:}

This is the proportion of the bulk of solids contained in a soil to the soil's absolute volume i.e. the addition of solids and voids volume [9].

\section{GRAIN SIZE}

Grain size is the measure of individual grain diameter of a sediment and other granular material. This ranges from boulders to gravel through sand, silt and clay. The grain size scales commonly used are the Wentworth and Krumbein phi $(\varphi)$ scale and the International Scale ISO 14688-1:2002. How the grain sizes are distributed affects permeability [10], this distribution is commonly characterised using indices such as constant of uniformity $\left(\mathrm{cu}=\frac{P_{60}}{P_{10}}\right)$, constant of curvature $\left(\mathrm{cc}=\frac{P_{30}^{2}}{P_{10} P_{30}}\right)$ and particle size percentiles $(\mathrm{P} 10, \mathrm{P} 30$ etc.). The larger the constant of uniformity, the better the soil grading and the smaller the permeability and vice versa [11].

In particle size analysis, the following methods can be used to derive grain size:

\section{A. Sieve (Sifter) Analysis:}

This is a devise that separate disaggregated rock samples into their various particle size distribution using a mesh or sifts wanted material from unwanted materials. Sieve analysis is carried out using a stack of sieves, Fig. 1.

\section{B. Image Particle Analysis:}

Measurements using this technique is done using digital imaging. It includes particle size, particle shape and colour (basically grey scale). The basic process of this technique is shown in Fig. 2. The instrument records a spread based on the length of the particle and shapes rather than how spherical it is.

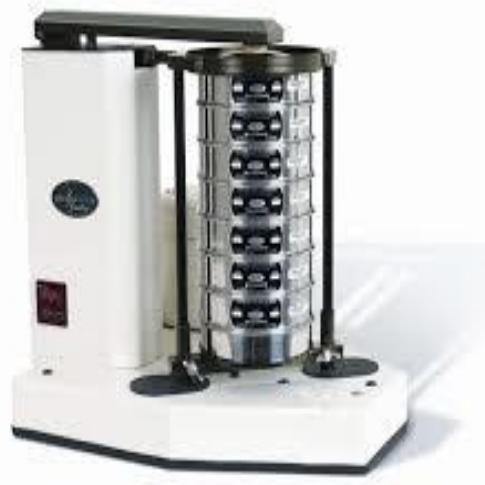

Fig. 1. Automated Sifter with different sieve sizes stacked on it [12].

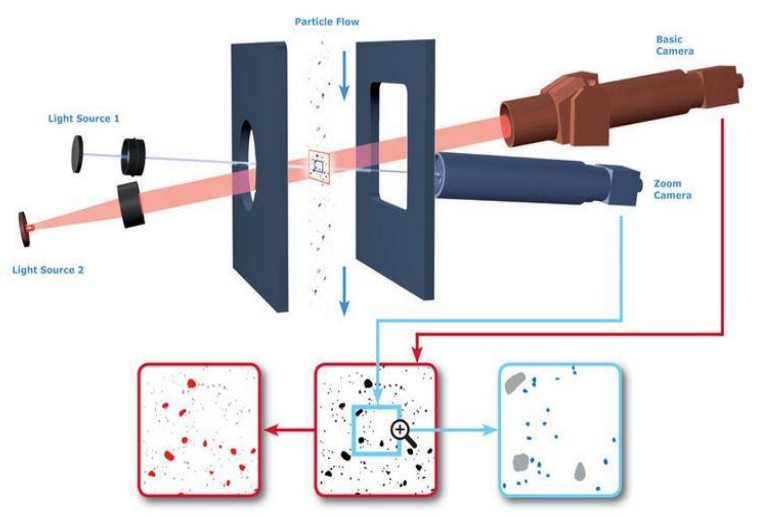

(a)

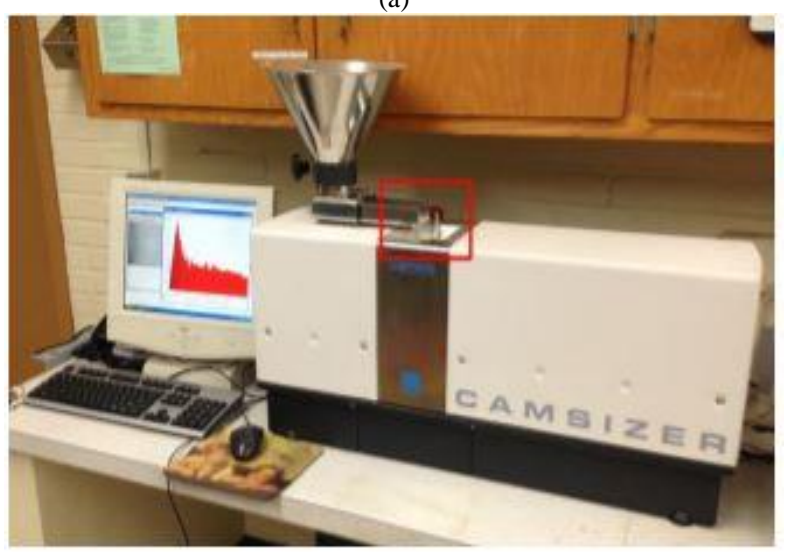

(b)

Fig. 2. (a) The principle behind the Camsizer (b) Typical Camsizer [13

\section{Laser Diffraction Analysis:}

This technology employs the use of diffraction method of passing a laser beam through objects ranging between 
nanometres to millimetres sizes, and measures quickly the geometrical dimensions of the particle. This technique is developed on Fraunhofer diffraction theory which states that the intensity of light scattered by a particle is directly proportional to the particle size, as shown in Fig. 3.
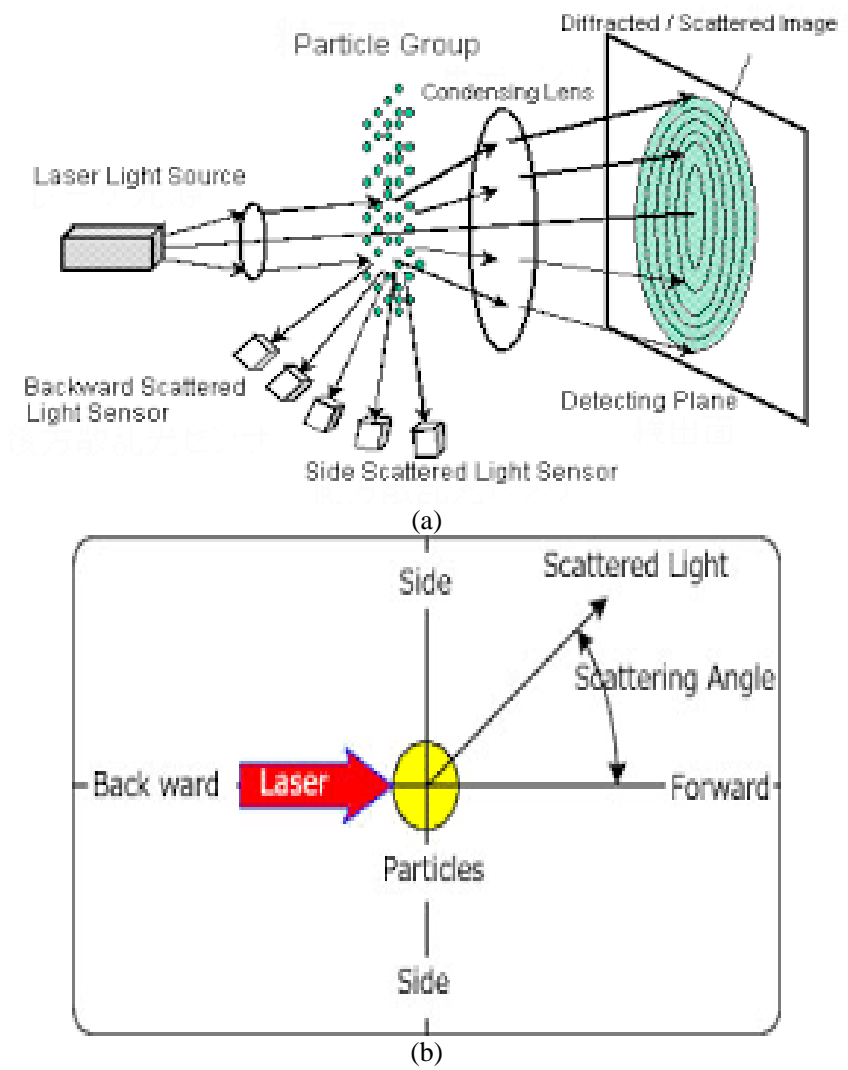

Fig. 2. (a) Laser diffraction analyser operating principle (b) Laser beam and particle interaction [14]

\section{LITERATURE REVIEW}

Reference [10] stated Hazen's empirical equation this equation is easy to use in permeability determination because it takes into consideration the $10^{\text {th }}$ percent weight cumulative of the grain size, which is easily determined.

$$
k=C\left(D_{10}\right)^{2}
$$

Reference [2] noted a disadvantage as the consideration range is between 0.1 to $3.0 \mathrm{~mm}$ representing only the fine grain size fraction.

Where: K - Permeability coefficient $(\mathrm{cm} / \mathrm{s}), \mathrm{C}-$ Constant (0.4 to 1.2 ), and $\mathrm{D}_{10}-$ Grain size mesh equivalent of the $10^{\text {th }}$ cumulative weight percentage $(\mathrm{mm})$

Reference [15] posited a modified Kozeny's equation. This equation is empirical for permeability prediction using grain size sieve analysis data and only appropriate for soils having an effective grain size of above $3 \mathrm{~mm}$ (i.e. $\mathrm{D}_{10}>$ $3 \mathrm{~mm})$.

$$
k=\frac{g}{v} 8.3 \times 10^{-3}\left[\frac{\emptyset^{-3}}{(1-\emptyset)^{2}}\right] D_{10^{2}}
$$

Where; $\mathrm{k}$ - permeability coefficient $(\mathrm{cm} / \mathrm{s}), \mathrm{g}-$ standard gravity $\left(\mathrm{cm} / \mathrm{s}^{2}\right), \mathrm{v}$ - viscosity $\left(\mathrm{mm}^{2} / \mathrm{s}\right)$

$\varnothing$ - Porosity in fraction $(\%)$, and $\mathrm{D}_{10}$ - Grain size mesh equivalent of the $10^{\text {th }}$ cumulative weight percentage $(\mathrm{mm})$
Reference [16], in their work to determine the ease of flow in an aquitard, employed the use of a modified version of the above equation as given by Peck and Terzaghi.

$$
k=\frac{g}{v} C_{t}\left[\frac{\emptyset-0.13}{(1-\varnothing)^{1 / 3}}\right]^{2} D_{10^{2}}
$$

where; $C_{t}$ - coefficient of sorting $\left(6.1 \times 10^{-3}\right.$ to $\left.10.7 \times 10^{-3}\right)$, other parameters are as define above.

Reference [17] determined the hydraulic conductivity of a particular location using grain size analysis data by employing Sen and Alyamani equation, that allows for the use of the slope intercept of the $50^{\text {th }}$ and $10^{\text {th }}$ line of grain weight (\%) against mesh size. This equation is suitable for well graded soils and is stated below;

$$
k=1.5046\left[I_{0}+0.025\left(D_{50}-D_{10}\right)\right]^{2}
$$

Where; K - permeability ( $\mathrm{m} /$ day), $\mathrm{I}_{0}$ - slope intercept, $\mathrm{D}_{10}-$ Grain size mesh equivalent of the $5^{\text {th }}$ cumulative weight percentage $(\mathrm{mm})$, and $\mathrm{D}_{50}-$ Grain size mesh equivalent of the $5^{\text {th }}$ cumulative weight percentage $(\mathrm{mm})$.

Reference [18] published his model for the unconsolidated sands of Niger delta, using grain size result obtained from sieve analysis and he came up with two equations for permeability of less than 1000 and greater than 1000 . He verified his finding by correlating his result with the values of permeability obtained from routine core analysis. The permeability expression is stated as:

$$
\mathrm{k} \leq 1000 \mathrm{mD}
$$

$k=15.27 \operatorname{cov}^{-0.03}-16.28 s . d^{0.07}+0.7668 \operatorname{Davg}^{8.5}+1.7$

$$
\mathrm{k} \geq 1000 \mathrm{mD}
$$

$k=71068.35 \operatorname{Davg}^{11.2} \times \exp \left(\left(\frac{c o v}{s d}\right)^{\times 1.63}\right)$

Where; K - permeability (D), Davg - average grain diameter (mm), s.d - sorting term (phi), and cov coefficient of variation (phi/mm)

\section{METHOD}

Data obtained from the laboratory are subjected to analysis, to develop a model that can be used to predict permeability based on cumulative frequency distribution curve of weight (\%) and mesh size (phi). Data are obtained from 35 samples in the Central Niger Delta in Nigeria.

\section{A. Developing the Model}

The grain size fractions obtained from sieve analysis, their weight percentages and percentiles are used to carryout multiple regression to develop the model. Cumulative weight percent obtained from each samples are plotted against mesh size. This is to enable the extraction of data points from the curve. Fig. 4, shows the cumulative frequency distribution curve of one of the sample ID (Sample 9). Tenth and ninety percentiles (P10 \& P90) are read off from the curve of each sample. The mean of the 
distribution is estimated from each sample using the equation below:

$$
x_{m s}=\frac{\sum_{i=0}^{n}\left(c w_{i} x_{m s i}\right)}{\sum_{i=1}^{n}\left(c w_{i}\right)}
$$

Where; cwi - Cumulative weight $(\%), \mathrm{x}_{\mathrm{msi}}-$ Mesh size (phi), $\mathrm{n}$ - Number data point in the series.

The model function is defined as:

$$
k=f\left(x_{m s}, P 10, P 90\right)
$$

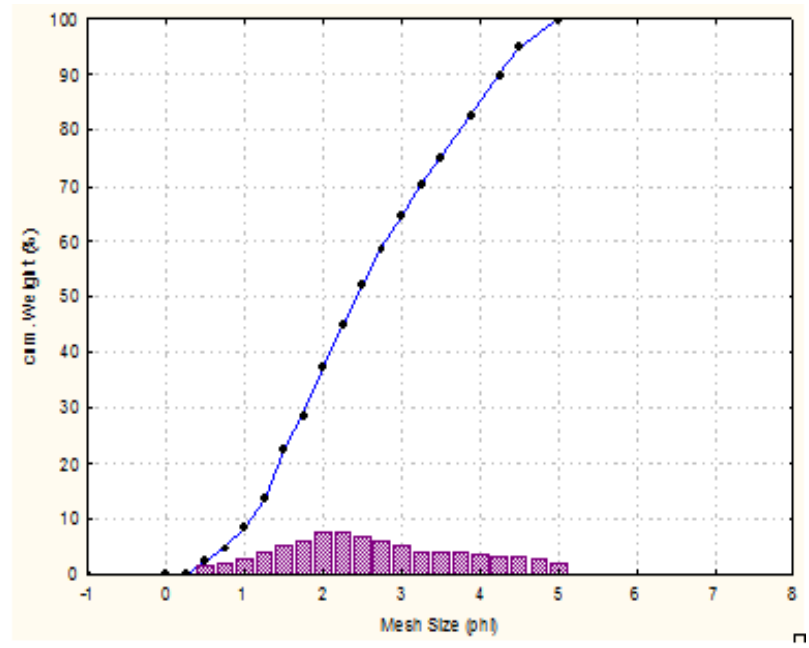

Fig. 4. Grain Size Analysis Curve (PSA Curve)

STATISTICA 7 software was utilized in developing the model. The choice of the software is to generate statistical indicators, which are used in the analysis of the model.

The data points are imported from Microsoft excel file into the software. Three models, each were entered into the user-special model environment and was simulated to determine the model parameters.

\section{RESULTS AND DISCUSSION}

The multiple regression analysis performed on the grain size data obtained from sieve analysis resulted in the development of three permeability prediction models with their statistical indicators. The models were developed for three different permeability ranges from less than $10 \mathrm{mD}$ to greater than $10000 \mathrm{mD}$. The models are shown below:

Model A: For $\mathrm{K}<10 \quad\left(\mathbf{R}^{2}=0.857, \mathbf{R}=0.926\right)$

$k=-a_{0} P 90+a_{1}\left(\frac{P 90}{P 10}\right)^{-a_{2} X_{m s}} \exp \left(-a_{3}\left(\frac{P 10+P 90}{X_{m s}}\right)\right)$

Where $\mathrm{a}_{0}, \mathrm{a}_{1}, \mathrm{a}_{2}$ and $\mathrm{a}_{3}$ are constants denoted by -1.2260 , $106.1442,-0.1386$ and -1.2887 respectively.

Model B: For $10<\mathrm{k}<10000\left(\mathbf{R}^{2}=0.82, \mathbf{R}=0.906\right)$

$$
k=-9358.13+\omega_{1} x_{m s}^{6.38}+\omega_{2} x_{m s}^{4.55}
$$

where

$$
\begin{aligned}
& \omega_{1}=12.6 P 10-20.38 x_{m s}+4.27 P 90 \\
& \omega_{2}=-81.85 P 10+201 x_{m s}-48.54 P 90
\end{aligned}
$$

Model C: $K>10,000\left(\mathbf{R}^{2}=0.9394, \mathbf{R}=0.969\right)$

$$
k=-a_{0} P 10-\left(a_{1} P 90^{-a_{2} X_{m s}}\right)-\frac{a_{3}}{P 10-P 90}
$$

Where $a_{0}, a_{1}, a_{2}$ and $a_{3}$ are $-17884,6526,-0.238$ and 126145 respectively.

The developed models are non-linear with normal distribution curve skewed to the left as shown in Fig. 5, 6, and 7 below.

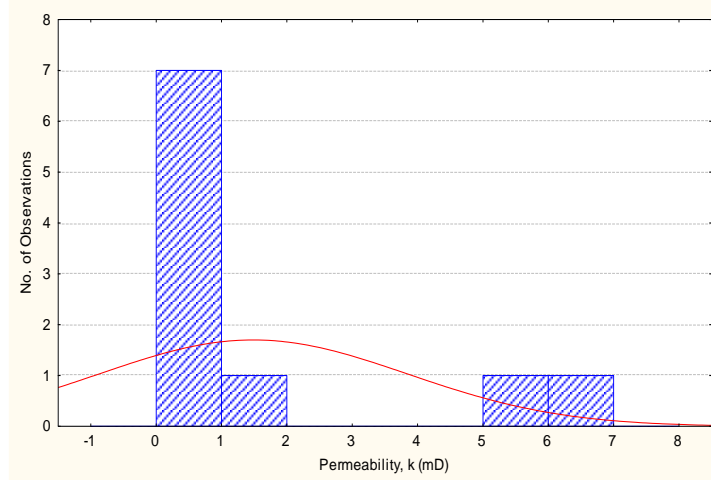

Fig. 5. Normal distribution curve for Model A

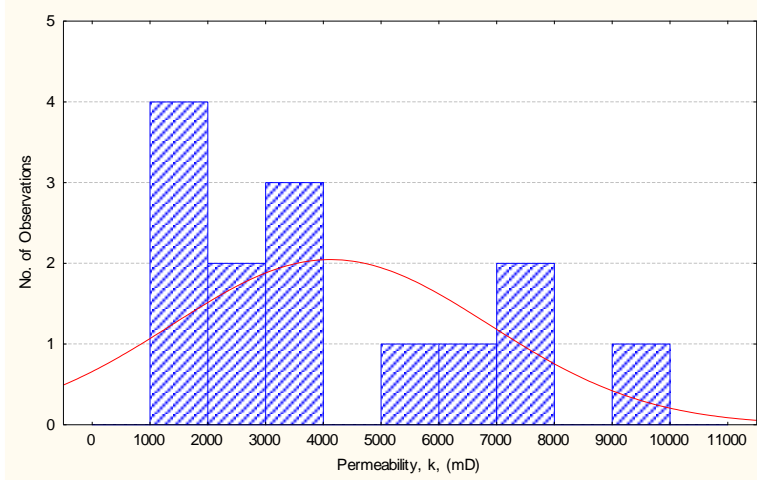

Fig. 6. Normal distribution curve for Model B

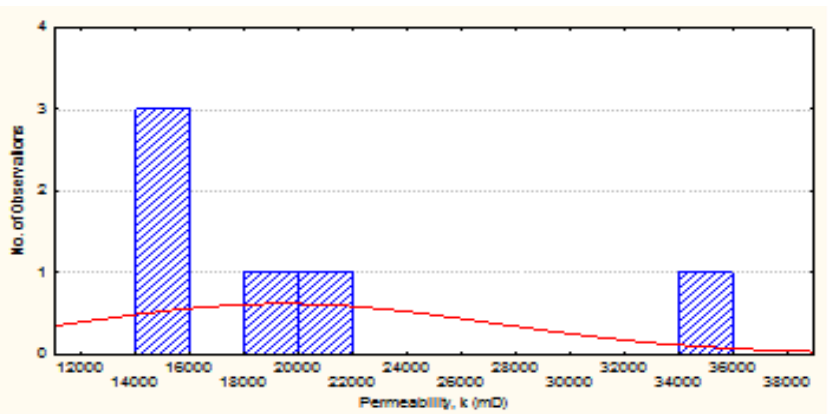

Fig. 7. Normal distribution curve for Model C

\section{A. 3D Prediction Plot}

Considering the effect of density on permeability, a relationship was established between permeability, density and grain size to develop a 3D prediction surface as shown in the Figure below. The colour represents permeability values at different ranges. As shown in the Figure, with increase in density there is a decrease in permeability, since the higher density values tends toward green colour which indicates lower permeability values. 


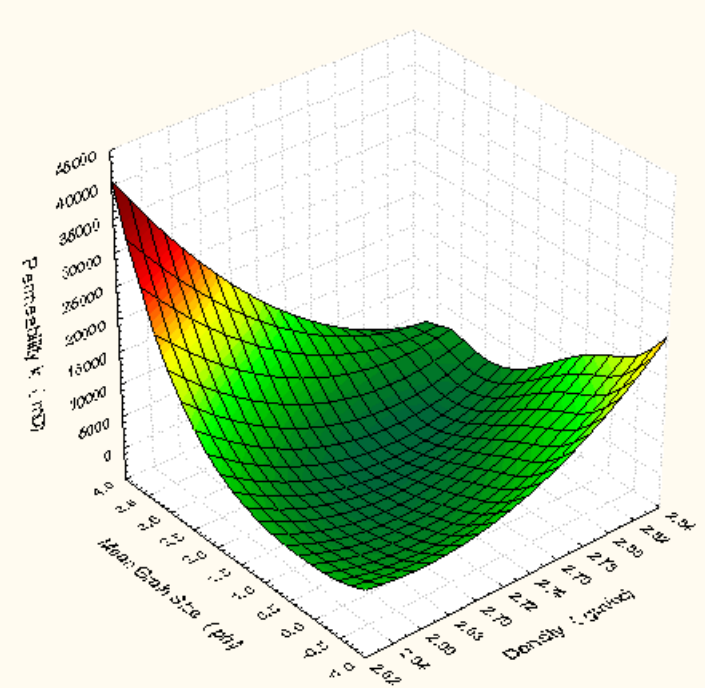

Fig. 8. 3D Surface Plot of Permeability (mD), Mean grain size (phi) and Density (gm/cc).

\section{B. Model Validation}

Adetiloye (2016), model, was compare with the model developed in this work. The choice for selecting this model is the fact that it was developed for the Niger Delta region using parameters such as the average grain diameter(Davg), sorting term(s.d), covaraince(cov) and model constants as shown in Equations (7) and (8). Equation 8 of the two Models was used in comparism with Model $\mathrm{C}$ developed in this work, because both models allow for calculation of permeability values that are greater than $1000 \mathrm{mD}$.

The analysis result is seen in Table 1, and it is observed that there are large variations in the predicted permeability which can result from the parameters used in the models. Adetiloye's model considered constants that may have caused the variation as a result of the heterogeneity of the Niger Delta sands. Kenny and Hazen's model equation considered a fraction of the grain distribution which doesn't represent the whole distribution.

TABLE I: MODEL COMPARISON TABLE

\begin{tabular}{cccccc}
\hline $\begin{array}{c}\text { Sample } \\
\text { ID }\end{array}$ & $\begin{array}{c}\text { RCA } \\
\text { Observed }\end{array}$ & $\begin{array}{c}\text { Adetiloye } \\
\text { Predicted }\end{array}$ & $\begin{array}{c}\text { Hazen } \\
\text { Predicted }\end{array}$ & $\begin{array}{c}\text { Kenney } \\
\text { Predicted }\end{array}$ & Model C \\
\hline $\mathbf{5 7}$ & 14230 & 7404.679 & 0.2209 & 0.0028125 & 18769.43 \\
$\mathbf{6 1}$ & 14240 & 5260.586 & 0.04 & 0.00045 & 15661.97 \\
$\mathbf{6 5}$ & 14770 & 16651.484 & 0.5776 & 0.00638 & 17830.57 \\
$\mathbf{6 9}$ & 18580 & 12045.279 & 0.3481 & 0.005 & 16732 \\
$\mathbf{8 9}$ & 20060 & 19624.071 & 0 & 0 & 19550.29 \\
$\mathbf{1 1 3}$ & 34500 & 344.9824 & 0.0225 & 0.000128 & 34282.93 \\
\hline \hline
\end{tabular}

\section{Model Validation Chart}

The developed models are validated with the permeability values gotten from the routine core analysis and it is plotted alongside the predicted permeability for each of the developed model as shown in Fig. 8, 9, and 10 below, which gives a visual representation of the model and analysis differences.

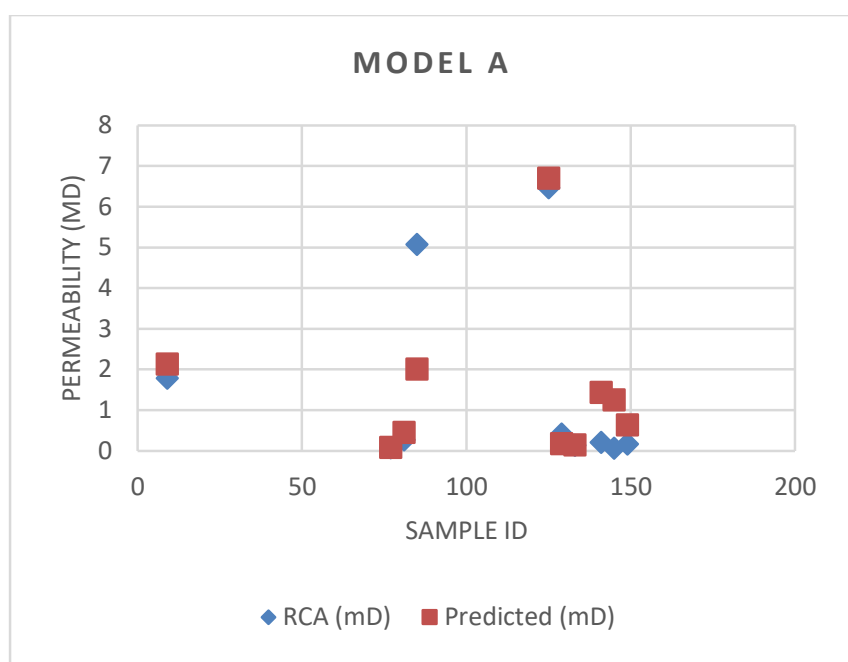

Fig. 8. Model A Validation Chart

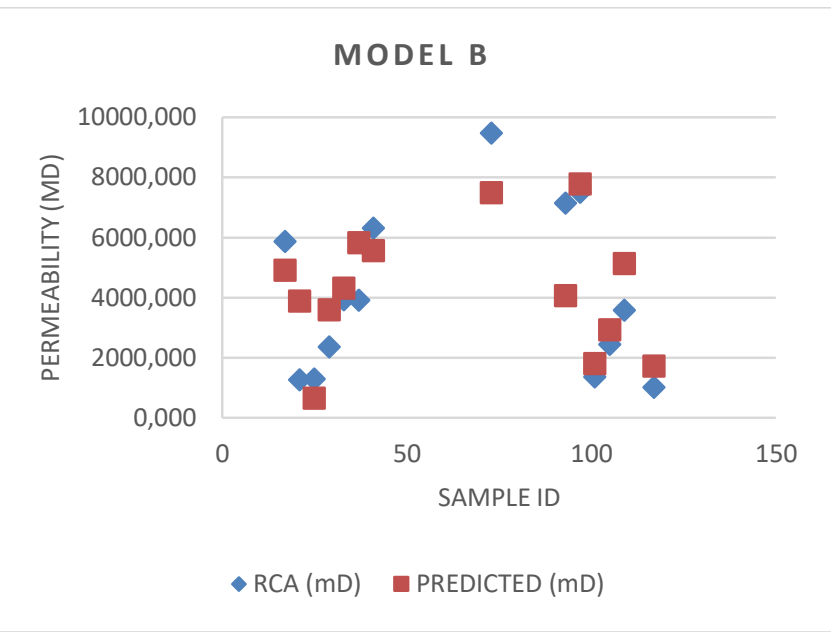

Fig. 9. Model B Validation Chart

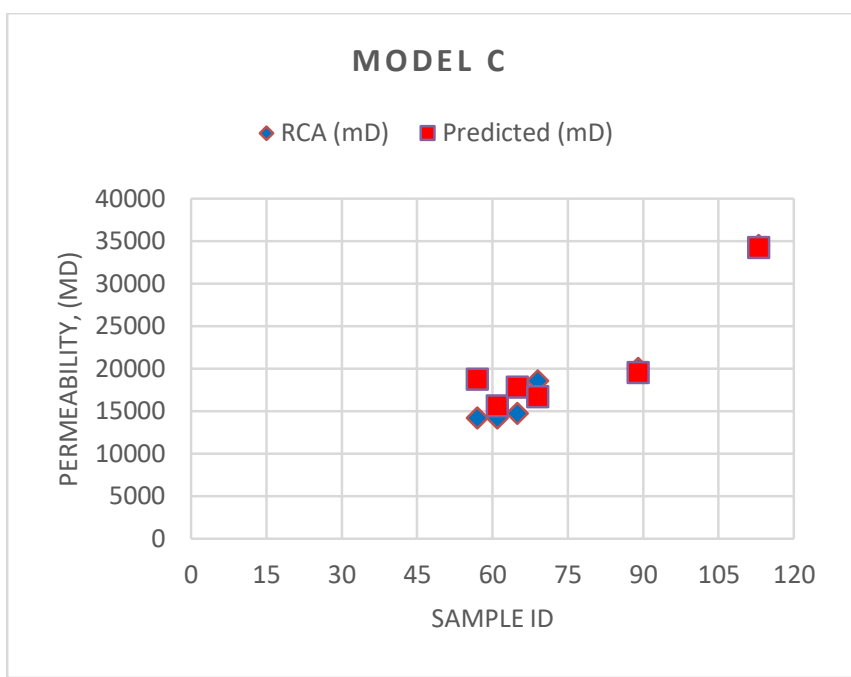

Fig. 10. Model C Validation Chart

\section{Model Sensitivity}

To examine the changes in permeability when mean mesh size distribution, $\mathrm{P} 10$ and $\mathrm{P} 90$ are varied, a sensitivity analysis was carried out. To properly understand the changes in the target variable (permeability) as the input varibles are varied, a MATLAB program was developed to generate a surface plot of the three models.

The permeability and mean mesh size axis of Model A, reveals that mean mesh size above 3.45 , are good prediction 
of permeability. Similarly, value of P10 and P90 above 4.3, shows that an increase in grain size leads to an increase in permeability.

As P10 and P90 value increase, the permeability of Model $\mathrm{B}$ increases signifying that $\mathrm{P} 10 / \mathrm{P} 90$ are good indicators for permeability estimation. The value of $\mathrm{P} 10 / \mathrm{P} 90$ above 1.5 shows that permeability increases as mean mesh size decreases and below this value, permeability increase as mean mesh size increase. The later signifies that proper sorting of the grain size can lead to high permeability.

Sensitivity plot for Model C, exhibits similar analysis as that of Model B. it differs in that the value of P10/P90 above 0.0 shows that permeability increase as mean mesh size decrease and below this value, permeability increases as mean mesh size increases. These variations are as a result of grain sorting and grading. At higher permeability values, because of Vugs, fractures and heterogeneity, the uncertainty level is increased. The importance of proper grain sorting can be observed from this plot.

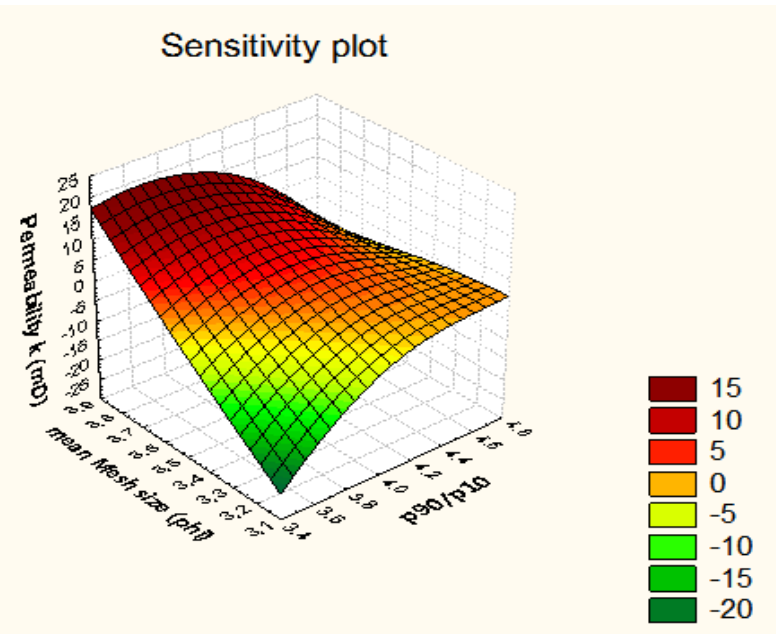

Fig. 11. Sensitivity plot if Model A

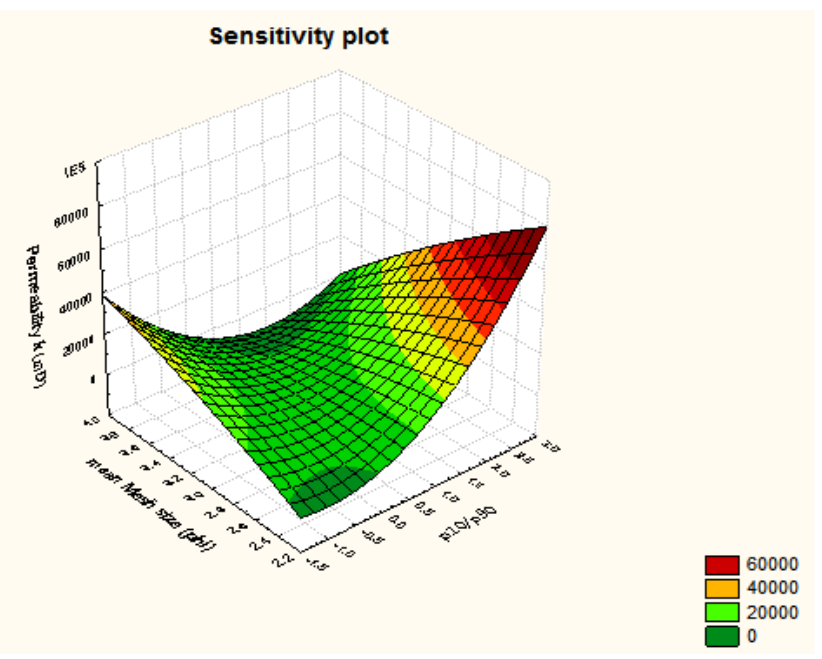

Fig. 12. Sensitivity plot if Model B
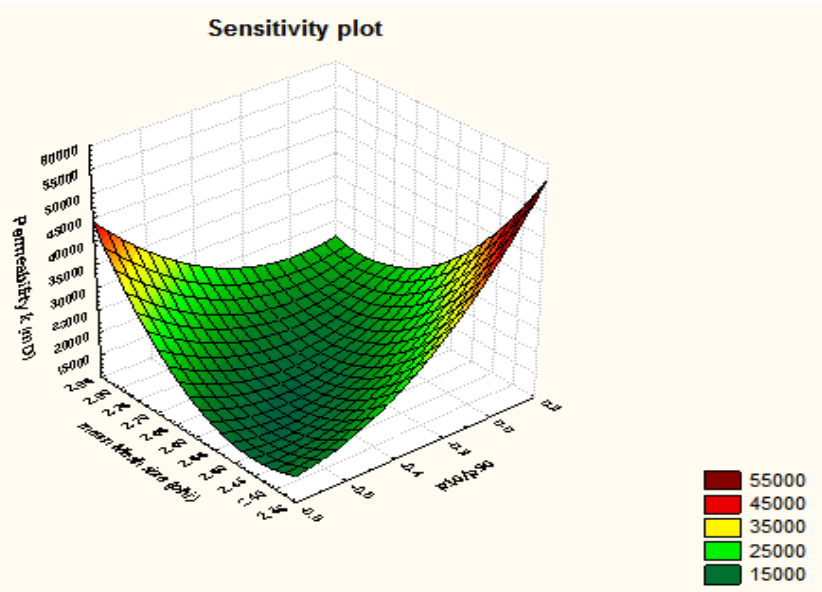

Fig. 13. Sensitivity plot if Model C

\section{CONCLUSION}

The complexities of permeability are dependent on grain size, distribution, shape and density which acts as determinants as to the interconnectivity of the pores in sands. Therefore, the developed models for permeability prediction were built to accommodate different ranges of permeability from as low as $<10$ to as high $>10000$. Because of these permeability controlling factors, developing a prediction model of $100 \%$ accuracy is impossible.

Variables used in developing the model are gotten from percentile grain distribution and a mean distribution index calculated from the cumulative weight percentage so as to get a proper representation of the whole sample distribution. Correlation of parameters in the models show strong positive affinity between parameters. All three models are advanced non-linear models with constants and coefficients.

Succeeding literature review, laboratory procedure and statistical analysis, and the outcomes of this work, are outlined as follows;

1) The models developed have multiple determination coefficients of 0.82 to 0.94 showing that the model fits well with the data.

2) The result from the comparison affirms the reason why empirical equations are not certainly transferable from region to region due to soil heterogeneity.

3) The sensitivity analysis shows the importance of proper grain sorting in permeability determination.

4) The 3D surface plot displays the relationship between permeability, density and grain size distribution. This surface can be used concurrently to assess the impact of grain size distribution and density on permeability.

\section{APPENDIX}

Statistic Indicators of the Models

Model A

TABLE B-2: Parameter Estimate

\begin{tabular}{ccccccc}
\hline \hline & Estimate & $\begin{array}{c}\text { Standard } \\
\text { error }\end{array}$ & $\begin{array}{c}\text { t-value } \\
\text { df = 6 }\end{array}$ & p-level & $\begin{array}{c}\text { Lo. } \\
\text { Conf. } \\
\text { Limit }\end{array}$ & $\begin{array}{c}\text { Up. } \\
\text { Conf. } \\
\text { Limit }\end{array}$ \\
\hline a0 & -1.2260 & 3.9999 & -0.3065 & 0.76957 & -11.01 & 8.561 \\
a1 & 106.144 & 607.071 & 0.17485 & 0.86695 & -1379.3 & 1591.59 \\
$\mathbf{a 2}$ & -0.1386 & 0.3881 & -0.3572 & 0.7332 & -1.09 & 0.811 \\
$\mathbf{a 3}$ & -1.2887 & 4.0516 & -0.3181 & 0.76121 & -11.2 & 8.625 \\
\hline \hline
\end{tabular}


MODEL B

TABLE B-6: Parameter Estimate

\begin{tabular}{|c|c|c|c|c|c|c|}
\hline & Estimate & $\begin{array}{c}\text { Standard } \\
\text { error }\end{array}$ & $\begin{array}{c}\text { t-value } \\
\text { df }=5\end{array}$ & p-level & $\begin{array}{c}\text { Lo. } \\
\text { Conf. } \\
\text { Limit }\end{array}$ & $\begin{array}{c}\text { Up. } \\
\text { Conf. } \\
\text { Limit }\end{array}$ \\
\hline a0 & -9358.1 & 72191.6 & -0.1296 & 0.90191 & -194932 & 176216 \\
\hline a2 & 12.6 & 2064.82 & 0.0061 & 0.99537 & -5295 & 5320.4 \\
\hline $\mathbf{a 3}$ & -20.38 & 3556.02 & -0.0057 & 0.99565 & -9161 & 9120.7 \\
\hline a4 & 4.27 & 617.05 & 0.00693 & 0.99474 & -1582 & 1590.4 \\
\hline a9 & 6.38 & 73.78 & 0.08649 & 0.93444 & -183 & 196 \\
\hline a5 & -48.54 & 822.87 & -0.059 & 0.95524 & -2164 & 2066.7 \\
\hline a6 & 201 & 3962.59 & 0.05073 & 0.96151 & -9985 & 10387.2 \\
\hline a7 & -81.85 & 1227.59 & -0.0667 & 0.94942 & -3237 & 3073.8 \\
\hline a8 & 4.55 & 77.71 & 0.05857 & 0.95556 & -195 & 204.3 \\
\hline
\end{tabular}

MODEL C

TABLE B-10: Parameter Estimate

\begin{tabular}{ccccccc}
\hline \hline & $\begin{array}{c}\text { Estimat } \\
\mathbf{e}\end{array}$ & $\begin{array}{c}\text { Standar } \\
\mathbf{d} \text { error }\end{array}$ & $\begin{array}{c}\text { t-value } \\
\mathbf{d f = 2}\end{array}$ & p-level & $\begin{array}{c}\text { Lo. } \\
\text { Conf. } \\
\text { Limit }\end{array}$ & $\begin{array}{c}\text { Up. } \\
\text { Conf. } \\
\text { Limit }\end{array}$ \\
\hline $\mathbf{a}$ & -17884 & \multirow{2}{*}{33153.0} & - & 0.64359 & - & 124761. \\
$\mathbf{0}$ & & & 0.539451 & 9 & 160530 & 3 \\
$\mathbf{a}$ & -65262 & \multirow{2}{*}{141993.3} & - & 0.69092 & - & 545686. \\
$\mathbf{1}$ & & & 0.459610 & 0 & 676210 & 4 \\
$\mathbf{a}$ & -0.238 & \multirow{2}{*}{0.3} & - & 0.56561 & -2 & 1.3 \\
$\mathbf{2}$ & & & 0.682024 & 2 & - & 556743. \\
$\mathbf{a}$ & -126145 & \multirow{2}{*}{158713.4} & - & 0.51006 & - & 8 \\
$\mathbf{3}$ & & & 0.794798 & 5 & 809034 & 8 \\
\hline \hline
\end{tabular}

\section{REFERENCES}

[1] Salarashayeri, A.A. "Prediction of soil hydraulic conductivity from particle-size distribution". World Academy of Science, Engineering and Technology, 61, 454-458, 2012.

[2] Holtz, R.K. "An introduction to Geotechnical Engineering”. PrenticeHall, Upper Saddle River, NJ, 853, 2011.
[3] DeGroot, D. Ostendorf, D. and Judge, A. "In situ measurement of hydraulic conductivity of saturated soils". Geotechnical Engineering Journal of the SEAGS and AGSSEA, 43(4): 63-72, 2012.

[4] Pingping Sun, M.Z. "An In-situ Darcy Method for Measuring Soil Permeability of Shallow Vadose Zone". Switzerland: Springer International Publishing, 2014.

[5] Kenney, T., Lau, D. and Ofoegbu, G. "Permeability of compacted granular materials" Canadian Geotechnical Journal, 21, 726-729, 1985.

[6] Detmer, M.D. "Permeability, Porosity, and Grain-size Distribution of Selected Pliocene and Quaternary Sediments in the Albuquerque Basin". New Mexico: New Mexico Institute of Mining and Technology, 1995.

[7] Pettijohn F.J. "Sedimentary Rocks" 3rd edition. New york: Harper and Row, 1975.

[8] Krumbein, W. A. "Stratigraphy and Sedimentation", Second Edition 660. San Francisco, W.H. Freeman and Company, 1963.

[9] Das, B. "Advanced soil mechanics". Taylor and Francis Pub. New York, NY, 2008

[10] Onur, E. M. "Predicting the Permeability of Sandy Soils from Grain size Distributions" A thesis submitted to Kent State University. Kent, Ohio, United States of America, May, 2014.

[11] Mitchell, J. and Soga, K. "Fundamentals of Soil Behavior" 592. Hoboken, New Jersey: John Wiley and Sons Inc., 2005.

[12] http://www.wstyler.com

[13] http://www.mep.net.au

[14] http://www.shimadzu.com

[15] Carrier, W. "Goodbye Hazen"; Hello Kozeny-Carmen. Geotechnical and Geoenvironmental Engineering, 2003.

[16] Cheng, C. and Chen, X. "Evaluation of methods for determination of hydraulic properties in an aquifer-aquitard system hydrologically connected to river". Hydrogeology Journal, 15, 669-678, 2007.

[17] Odong, J. "Evaluation of the empirical formulae for determination of hydraulic conductivity based on grain size analysis": American Science, 3, 54-60, 2007.

[18] Adetiloye, B. Model for Quick Permeability Determination of Niger Delta Sands Using Grain Size Analysis. Society of Petroleum Engineers, 23, 1-12, 2016. 